\title{
DESIGN AND EVALUATION OF NIFEDIPINE FLOATING MATRIX TABLETS
}

Rohit Jaimini ${ }^{1}$, Dr. Mayank Bansal ${ }^{2}$

${ }^{1}$ Research Scholar, Department of Pharmaceutics, Jaipur College of Pharmacy, Jaipur, Rajasthan, India

${ }^{2}$ Professor and Principal, Jaipur College of Pharmacy, Jaipur, Rajasthan, India

Article Info: Received 17 February 2020; Accepted 28 March 2020

DOI: https://doi.org/10.32553/jbpr.v9i2.730

Address for Correspondence: Rohit Jaimini

Conflict of interest statement: No conflict of interest

\begin{abstract}
:
Floating drug delivery systems are retained in the stomach and are useful for drugs that are poorly soluble or unstable in intestinal fluid. Floating drug delivery system have a bulk density less than that of gastric fluids and so remain buoyant in the stomach without affecting the gastric emptying rate for a prolong period of time. Research work emphasized on design and evaluates nifedipine floating matrix tablets in which polymers i.e. hydroxyprophyl methyl cellulose (HPMC $\mathrm{K} 100 \mathrm{M}, \mathrm{K} 4$, and K15) was used. About 15-35 \% of HPMC can be used as a polymer in the extended release formulations. So, here the polymer was used in the range of $16-36 \%$. Sodium bicarbonate $(40 \%)$ is used as a gas generating agent. It can be used in the range of 25-50\%. The granules are prepared by wet granulation method. The prepared granules were evaluated for the bulk density, tapped density, bulkiness, angle of repose, compressibility index and hausner ratio. The values indicate good flow property. The compressed tablets were evaluated for hardness, uniformity of weight, friability, drug content, buoyancy lag time and duration of buoyancy. All the readings are within the prescribed limits. There was no interaction between the drug, polymer and excipients it was found out by IR studies. The in vitro drug release data indicate that the release of the drug depends upon the proportion of polymer present in the formulation. As the polymer ratio increases the release rate of the drug is prolonged.
\end{abstract}

Keywords: Floating tablet, HPMC K100M, nifedipine, HPMC K4

\section{Introduction}

Several difficulties are faced in designing controlled release systems for better absorption and enhanced bioavailability. One of such difficulties is the inability to confine the dosage form in the desired area of the gastrointestinal tract. Drug absorption from the gastrointestinal tract is a complex procedure and is subject to many variables. It is widely acknowledged that the extent of gastrointestinal tract drug absorption is related to contact time with the small intestinal mucosa. Thus, small intestinal transit time is an important parameter for drugs that are incompletely absorbed. Floating drug delivery system have a bulk density less than that of gastric fluids and so remain buoyant in the stomach without affecting the gastric emptying rate for a prolong period of time. While the system is floating on the gastric contents, the drug is released slowly at the desired rate from the system. After release of drug, the residual system is emptied from the stomach. This result in an increased GRT and a better control of fluctuation in plasma drug concentration.

Materials and Methods:
Table 1: The chemical and solvent used in the present investigation

\begin{tabular}{lll}
\hline S.NO. & NAME & Supplier / Manufacturer \\
\hline 1 & Nifedipine & Unichem laboratories Ltd, Mumbai \\
\hline 2 & HPMC K4 M & Anil Enterprises Delhi. \\
\hline 3 & HPMC K15 M & samson laboratories pvt .Itd. solan himachal Pradesh \\
\hline 4 & HPMC K100 M & samson laboratories pvt. Itd. solan himachal Pradesh \\
\hline 5 & Sodium bicarbonate & Central drug house p.Itd. ,New Delhi \\
\hline 6 & Lactose & Loba chemie Pvt. Ltd-Mumbai \\
\hline 7 & Ethyl Cellulose & Loba chemie Pvt. Ltd-Mumbai \\
\hline 8 & Talc & Loba chemie Pvt. Ltd-Mumbai \\
\hline 9 & Magnesium Stearate & Loba chemie Pvt. Ltd-Mumbai \\
\hline 10 & Poly propyl alcohol & from Nice chemicals Pvt. Ltd-Cochin \\
\hline 11 & Starch & Loba chemie Pvt. Ltd-Mumbai \\
\hline
\end{tabular}

Table 2: List of instruments and equipments

\begin{tabular}{lll}
\hline S. No. & Name & Manufacturer with model \\
\hline 1 & Melting point Apparatus & Macro Scientific works,403 \\
\hline 2 & Digital Weighing Balance & Fisher brand, PS-200 \\
\hline 3 & Double beam UV Spectrophotometer & Systronics 2203 \\
\hline 4 & Differential scanning Calorimeter(DSC) & Perkin Elimer,Pyris,DSC,USA \\
\hline 5 & Infra Red Spectrophotometer & Shimadzu FTIR,5300 \\
\hline 6 & Incubator & Instrument India, Mumbai \\
\hline 7 & Six Basket Dissolution Appratus & Lab India DT 8000 \\
\hline 8 & Magnetic stirrer & Instrument India, Mumbai \\
\hline 9 & Heating mental & Instrument India, Mumbai \\
\hline 11 & pH meter & Instrument India, Mumbai \\
\hline 12 & Tablet machine & Shakti Pharma Tech, Gujarat \\
\hline
\end{tabular}




\section{Calibration Curve of Nifedipine:}

Principle: The calibration curve is based on the spectrophotometry. The maximum absorption was observed at $350 \mathrm{~nm}$. It obeyed Beer's law in the concentration range of $2-20 \mu \mathrm{g} / \mathrm{ml}$.

\section{Standard stock solution:}

The stock solutions was freshly prepared by dissolving $100 \mathrm{mg}$ of nifedipine in a $100 \mathrm{ml}$ volumetric flask and then make up the solution up to the mark using $0.1 \mathrm{~N}$ $\mathrm{HCl}$ for obtaining the solution of strength $1000 \mu \mathrm{g} / \mathrm{mL}$ (stock I). $10 \mathrm{ml}$ of this solution is diluted to $100 \mathrm{ml}$ with $0.1 \mathrm{~N} \mathrm{HCl}$ to obtain a solution of strength $100 \mu \mathrm{g} / \mathrm{mL}$ (stock II). From this secondary stock required concentrations $2,4,6,8,10,12,14,16,18$ and $20 \mu \mathrm{g} / \mathrm{mL}$ was prepared. The absorbance was measured at $350 \mathrm{~nm}$ using a UV spectrophotometer.

\section{Preparation of Nifedipine floating matrix tablets:}

Tablets containing Nifedipine were prepared by wet granulation method. The respective powders drug, polymers (HPMC K4M, HPMC K 15M, HPMC K100M), sodium bicarbonate, lactose were blended thoroughly with mortar and pestle. The powder blend was then lubricated with magnesium stearate and talc mixed for about 3 minutes. The required amount of the blend was weighed and finally this mixture was compressed on a 10-station rotary tablet machine using $10-\mathrm{mm}$ standard flat-face punches

Table 3: Preparation of floating tablet of Nifedipine

\begin{tabular}{|c|c|c|c|c|c|c|c|c|c|c|c|c|}
\hline Formulation & 21 & 22 & 23 & 24 & 25 & 26 & 27 & 28 & 29 & 210 & 211 & 212 \\
\hline DRUG(mg) & 40 & 40 & 40 & 40 & 40 & 40 & 40 & 40 & 40 & 40 & 40 & 40 \\
\hline HPMC K4M(mg) & 50 & 70 & 50 & 70 & - & & & - & - & - & - & - \\
\hline HPMCK15M(mg) & - & - & 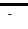 & - & 50 & 60 & 50 & 60 & - & & & \\
\hline $\begin{array}{l}\text { HPMC } \\
\text { K100M(mg) }\end{array}$ & - & - & - & - & - & - & - & - & 70 & 60 & 70 & 60 \\
\hline 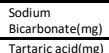 & 50 & 50 & 50 & 50 & 50 & 50 & 50 & 50 & 50 & 50 & 50 & 50 \\
\hline Citrric acid(mg) & - & - & 20 & 20 & 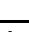 & - & 20 & 20 & $=$ & - & 20 & 20 \\
\hline$\overline{E C}$ & 40 & 50 & 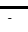 & - & 50 & 60 & - & $=$ & 55 & 65 & - & - \\
\hline MCC & - & - & 40 & 50 & - & - & 50 & 60 & - & 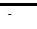 & 55 & 65 \\
\hline Lactose & 138 & 108 & 138 & 108 & 128 & 108 & 128 & 108 & 103 & 103 & 103 & 10 \\
\hline Talc & 6 & 6 & 6 & 6 & 6 & 6 & 6 & 6 & 6 & 6 & 6 & 6 \\
\hline Mag.Stearate & 6 & 6 & 6 & 6 & 6 & 6 & 6 & 6 & 6 & 6 & 6 & 6 \\
\hline
\end{tabular}

EVALUATION OF NIFEDIPINE FLOATING GRANULES:

Preformulation studies of powder drug of nifedipine performed according to standard procedure given in IP 1996 i.e. Angle of repose, Bulk density, Tapped density, Bulkiness: Compressibility index and hausner ratio.

\section{EVALUATION OF NIFEDIPINE FLOATING TABLETS:-}

\section{Tablet thickness:}

The thickness in millimeters $(\mathrm{mm})$ was measured individually for 10 pre weighed tablets by using vernier calipers. The average thickness and standard deviation were reported.

\section{Weight variation:}

Twenty (20) tablets from each batch were individually weighed in grams (gm) on an analytical balance. The average weight and standard deviation were calculated and the results were expressed as compliance or noncompliance of set limits.

\section{Hardness of the tablets:}

Ten tablets were measured in the hardness examination. Tablet hardness was measured using a Monsanto hardness tester.

\section{Friability of the tablets:}

Twenty tablets of the formulation were weighed and measured in a Roche type friabilator.

\section{The floating lag time and the total floating time:}

This test was characterized by floating lag time and total floating time. The test was performed using USP XXIII type II paddle apparatus using $900 \mathrm{ml}$ of $0.1 \mathrm{~N} \mathrm{HCl}$ at paddle rotation of $50 \mathrm{rpm}$ at $37 \pm 0.5 \mathrm{o} \mathrm{C}$. The time required for tablet to rise to surface of dissolution medium and duration of time the tablet constantly float on dissolution medium was noted as floating lag time and total floating time.

\section{Water uptake studies:}

The swelling behavior of dosage unit can be measured either by studying its dimensional changes, weight gain or water uptake. The water uptake study of the dosage form was conducted by using USP dissolution apparatus-II in a $900 \mathrm{ml}$ of distilled water which was maintained at $370+0.5 \mathrm{oc}$, rotated at $50 \mathrm{rpm}$. At selected regular intervals the tablet was withdrawn and weighed. Percentage swelling of the tablet was expressed as percentage water uptake (\%WU).

$\% \mathrm{WU}=(\mathrm{Wt}-\mathrm{Wo}) * 100 / \mathrm{Wo}$

Where Wt is the weight of the swollen tablet and Wo is the initial weight of the tablet.

\section{Drug-excipients interaction studies:}

The infrared spectra of pure drug, physical mixture of drug and excipients, polymer and formulation were recorded between 4000 to $400 \mathrm{~cm}-1$ on FTIR.

\section{Dissolution Study of tablets:}

The tablet was placed inside the dissolution vessel. $5 \mathrm{ml}$ of sample were withdrawn at time intervals of $0.5,1,2$, $3,4,6,8,10$ and $12 \mathrm{~h}$. The volume of dissolution fluid adjusted to $900 \mathrm{ml}$ by replacing $5 \mathrm{ml}$ of dissolution medium after each sampling. The release studies were 
conducted with 3 tablets, \& the mean values were plotted versus time. Each sample was analyzed at 301 $\mathrm{nm}$ using double beam UV and Visible Spectrophotometer against reagent blank. The drug concentration was calculated using standard calibration curve.

\section{RESULTS AND DISCUSSION:}

\section{Differential scanning calorimetry}

The sample preparations are sealed in aluminum pan and heated at constant ratio of $10^{\circ} \mathrm{C} / \mathrm{min}$ over a temperature range of $25^{\circ} \mathrm{C}-65^{\circ} \mathrm{C}$.

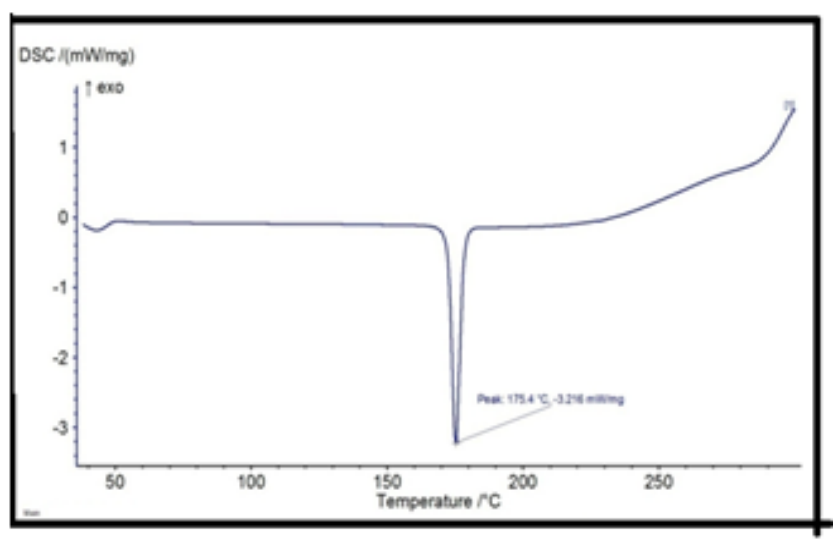

Figure 1: DSC of Nifedipine
Table 4: Determination of UV absorbance maxima of Nifedipine:

\begin{tabular}{ll}
\hline Con $^{\mathrm{c}}(\mathrm{ug} / \mathrm{ml})$ & Absorbance \\
\hline 0 & 0.000 \\
\hline 2 & 0.121 \\
\hline 4 & 0.242 \\
\hline 6 & 0.355 \\
\hline 8 & 0.468 \\
\hline 10 & 0.585 \\
\hline 12 & 0.651 \\
\hline 14 & 0.761 \\
\hline 16 & 0.821 \\
\hline 20 & 0.910 \\
\hline
\end{tabular}

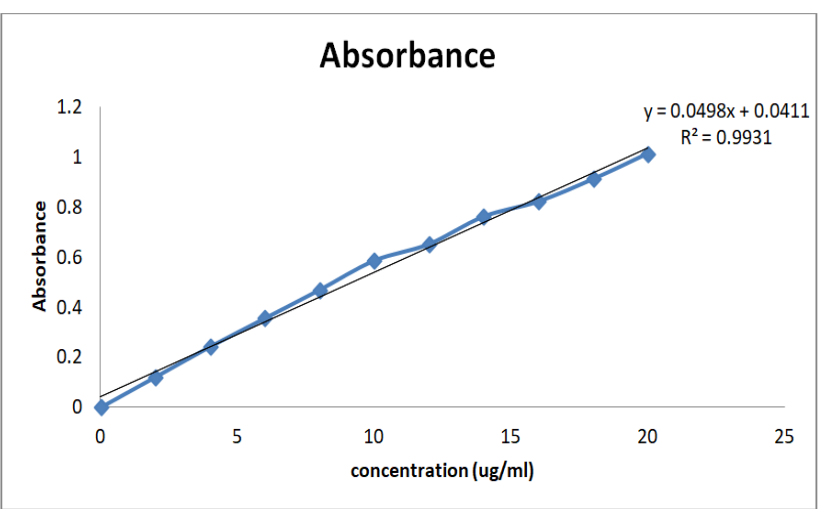

Figure 2: Standard curve of nifedipine in $0.1 \mathrm{~N} \mathrm{HCL}$ at $350 \mathrm{~nm}$

Table 5: Evaluation of Nifedipine granules for formulation

\begin{tabular}{|c|c|c|c|c|c|}
\hline Parameter & Angle of Repose $(\theta)$ & Bulk Density (mg/ml) & Tapped Density $(\mathrm{mg} / \mathrm{ml})$ & Hauners Ratio & Compressibility Index (\%) \\
\hline \multicolumn{6}{|l|}{ Formulation } \\
\hline $\mathrm{Z1}$ & $25.827 \pm 1.675$ & $0.673 \pm 0.010$ & $0.776 \pm 0.029$ & $1.152 \pm 0.023$ & $13.265 \pm 1.672$ \\
\hline $\mathrm{Z2}$ & $26.406 \pm 1.203$ & $0.589 \pm 0.023$ & $0.666 \pm 0.031$ & $1.131 \pm 0.025$ & $11.607 \pm 1.262$ \\
\hline $\mathrm{Z3}$ & $25.900 \pm 1.109$ & $0.628 \pm 0.031$ & $0.702 \pm 0.028$ & $1.117 \pm 0.027$ & $10.476 \pm 1.623$ \\
\hline $\mathrm{Z4}$ & $28.885 \pm 1.576$ & $0.661 \pm 0.028$ & $0.758 \pm 0.039$ & $1.149 \pm 0.031$ & $13.065 \pm 1.213$ \\
\hline $\mathrm{Z5}$ & $26.575 \pm 1.320$ & $0.611 \pm 0.033$ & $0.717 \pm 0.027$ & $1.148 \pm 0.008$ & $12.962 \pm 1.278$ \\
\hline 26 & $25.706 \pm 0.923$ & $0.634 \pm 0.007$ & $0.634 \pm 0.018$ & $1.130 \pm 0.023$ & $11.538 \pm 1.291$ \\
\hline $\mathrm{Z7}$ & $28.071 \pm 1.328$ & $0.568 \pm 0.025$ & $0.653 \pm 0.016$ & $1.115 \pm 0.032$ & $10.344 \pm 2.328$ \\
\hline Z8 & $27.348 \pm 1.134$ & $0.584 \pm 0.027$ & $0.640 \pm 0.026$ & $1.118 \pm 0.039$ & $10.619 \pm 1.259$ \\
\hline 29 & $26.706 \pm 0.914$ & $0.573 \pm 0.031$ & $0.694 \pm 0.023$ & $1.157 \pm 0.029$ & $10.434 \pm 1.906$ \\
\hline $\mathrm{Z10}$ & $26.565 \pm 0.973$ & $0.603 \pm 0.008$ & $0.660 \pm 0.013$ & $1.150 \pm 0.011$ & $13.636 \pm 2.018$ \\
\hline $\mathrm{Z11}$ & $28.787 \pm 1.004$ & $0.573 \pm 0.023$ & $0.680 \pm 0.036$ & $1.134 \pm 0.028$ & $11.818 \pm 0.775$ \\
\hline $\mathrm{Z12}$ & $28.298 \pm 1.281$ & $0.667 \pm 0.032$ & $0.715 \pm 0.031$ & $1.29 \pm 0.031$ & $11.447 \pm 1.243$ \\
\hline
\end{tabular}

Table 6: Post compression evaluation of nifedipine tablets

\begin{tabular}{|c|c|c|c|c|c|}
\hline Formula code & Weight variation(mg) & Hardness kg/cm2 & Thickness (mm) & Friability (\%) & Lag time (sec) \\
\hline $\mathrm{Z1}$ & $347 \pm 2.3$ & $4 \pm 0.5$ & $3.21 \pm 0.08$ & 0.26 & 30 \\
\hline $\mathrm{Z2}$ & $351 \pm 3.8$ & $4 \pm 0.5$ & $3.23 \pm 0.06$ & 0.23 & 39 \\
\hline $\mathrm{Z3}$ & $356 \pm 4.5$ & $4 \pm 0.3$ & $3.21 \pm 0.06$ & 0.48 & 20 \\
\hline $\mathrm{Z4}$ & $351 \pm 8.3$ & $4 \pm 0.5$ & $3.22 \pm 0.09$ & 0.51 & 30 \\
\hline $\mathrm{Z5}$ & $345 \pm 5.3$ & $4 \pm 0.2$ & $3.26 \pm 0.08$ & 0.22 & 18 \\
\hline Z6 & $349 \pm 2.3$ & $4 \pm 0.5$ & $3.21 \pm 0.05$ & 0.41 & 12 \\
\hline $\mathrm{Z7}$ & $353 \pm 5.5$ & $4 \pm 0.5$ & $3.24 \pm 0.05$ & 0.35 & 10 \\
\hline $\mathrm{Z8}$ & $344 \pm 5.6$ & $4 \pm 0.2$ & $3.28 \pm 0.02$ & 0.38 & 14 \\
\hline Z9 & $348 \pm 3.3$ & $4 \pm 0.5$ & $3.23 \pm 0.02$ & 0.41 & 32 \\
\hline $\mathrm{Z10}$ & $346 \pm 6.2$ & $4 \pm 0.3$ & $3.21 \pm 0.16$ & 0.29 & 21 \\
\hline Z11 & $351 \pm 4.3$ & $4 \pm 0.5$ & $3.28 \pm 0.05$ & 0.38 & 7 \\
\hline $\mathrm{Z} 12$ & $349 \pm 2.3$ & $4 \pm 0.4$ & $3.19 \pm 0.09$ & 0.41 & 12 \\
\hline
\end{tabular}


Table 7: Swelling index studies of Nifedipine floating tablets

\begin{tabular}{|c|c|c|c|c|c|c|c|c|c|c|c|c|}
\hline Time (hr) & $Z 1$ & $\mathrm{Z2}$ & $\mathrm{Z3}$ & $\mathrm{Z4}$ & $\mathrm{Z5}$ & Z6 & $\mathrm{Z7}$ & $\mathrm{Z8}$ & Z9 & $\mathrm{Z10}$ & Z11 & $\mathrm{Z12}$ \\
\hline 0 & 0 & 0 & 0 & 0 & 0 & 0 & 0 & 0 & 0 & 0 & 0 & 0 \\
\hline 2 & 32 & 35 & 35 & 42 & 36 & 38 & 35 & 38 & 36 & 39 & 35 & 34 \\
\hline 4 & 46 & 48 & 48 & 50 & 49 & 55 & 45 & 48 & 63 & 65 & 62 & 52 \\
\hline 6 & 52 & 55 & 55 & 58 & 62 & 78 & 54 & 59 & 73 & 75 & 72 & 65 \\
\hline 8 & 63 & 70 & 70 & 72 & 76 & 89 & 64 & 68 & 84 & 85 & 82 & 72 \\
\hline 10 & 88 & 91 & 88 & 91 & 99 & 110 & 74 & 79 & 99 & 102 & 110 & 98 \\
\hline 14 & 108 & 112 & 112 & 113 & 128 & 138 & 142 & 139 & 135 & 140 & 135 & 139 \\
\hline 18 & 140 & 135 & 130 & 155 & 180 & 177 & 172 & 181 & 160 & 165 & 162 & 174 \\
\hline
\end{tabular}

DRUG RELEASE STUDIES:

Table 8: In vitro release data of nifedipine - Zero-order release

\begin{tabular}{|c|c|c|c|c|}
\hline \multirow{2}{*}{$\begin{array}{l}\text { Time hr } \\
0\end{array}$} & \multicolumn{4}{|c|}{ Cumulative \% Drug Release } \\
\hline & $\mathrm{Z1}$ & $\mathrm{Z2}$ & $\mathrm{Z3}$ & $\mathrm{Z4}$ \\
\hline 0 & 0 & 0 & 0 & 0 \\
\hline 2 & 24.23 & 22.35 & 12.75 & 21.15 \\
\hline 4 & 35.45 & 26.21 & 32.56 & 34.15 \\
\hline 8 & 37.45 & 37.51 & 47.21 & 46.12 \\
\hline 12 & 45.48 & 48.24 & 64.23 & 52.12 \\
\hline 16 & 65.45 & 51.12 & 72.12 & 72.12 \\
\hline 18 & 77.25 & 67.25 & 84.29 & 78.31 \\
\hline
\end{tabular}

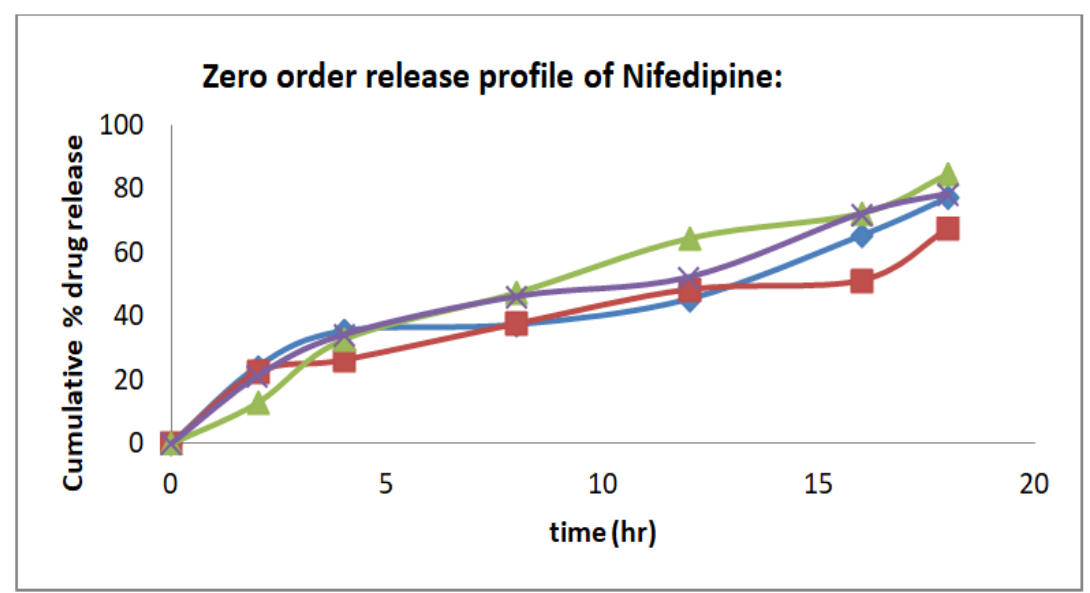

Figure 3: Zero order release profile of Nifedipine

Table 9: In vitro release data of nifedipine - First -order release

\begin{tabular}{|c|c|c|c|c|}
\hline \multicolumn{5}{|c|}{ cumulative Log $\%$ drug retained } \\
\hline Time & $\mathrm{Z1}$ & $\mathrm{Z2}$ & Z3 & Z4 \\
\hline 0 & 2 & 2 & 2 & 2 \\
\hline 2 & 1.87 & 1.89 & 1.94 & 1.89 \\
\hline 4 & 1.80 & 1.86 & 1.82 & 1.81 \\
\hline 8 & 1.79 & 1.79 & 1.72 & 1.73 \\
\hline 12 & 1.73 & 1.71 & 1.55 & 1.68 \\
\hline 16 & 1.53 & 1.68 & 1.44 & 1.44 \\
\hline 18 & 1.35 & 1.51 & 1.19 & 1.33 \\
\hline
\end{tabular}




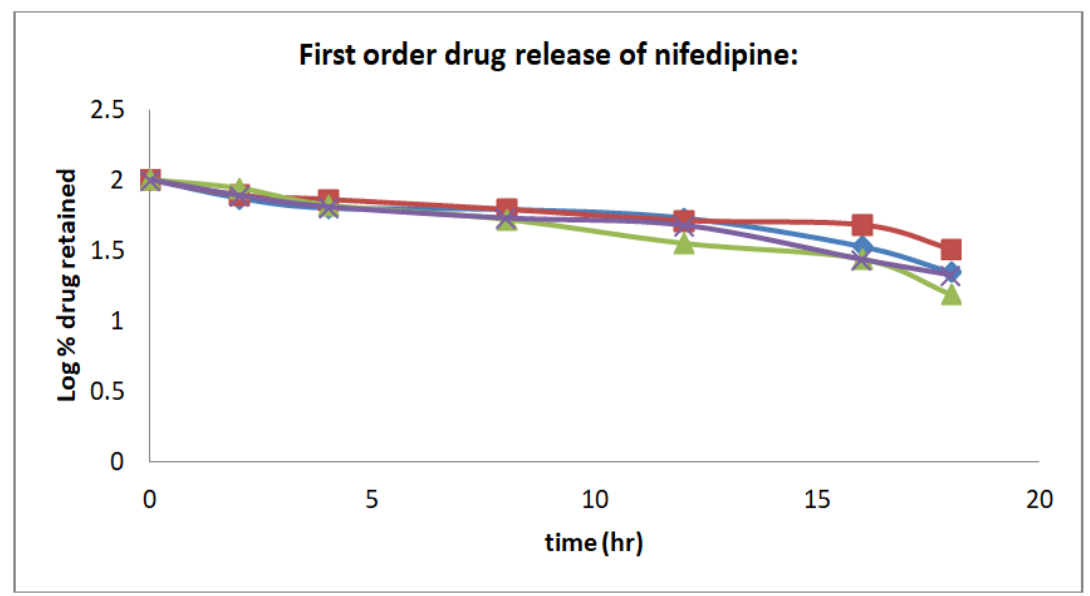

Figure 4: First order drug release profile of Nifedipine

Table 10: Fit of various kinetic models for floating tablet of nifedipine

\begin{tabular}{llll}
\hline Formulation code & Zero order R2 & First order R2 & Higuchi model R2 \\
\hline Z1 & 0.949 & 0.932 & 0.966 \\
\hline Z2 & 0.921 & 0.956 & 0.970 \\
\hline Z3 & 0.966 & 0.956 & 0.980 \\
\hline Z4 & 0.949 & 0.938 & 0.980 \\
\hline Z5 & 0.965 & 0.963 & 0.970 \\
\hline Z6 & 0.957 & 0.980 & 0.990 \\
\hline Z7 & 0.966 & 0.874 & 0.988 \\
\hline Z8 & 0.957 & 0.874 & 0.970 \\
\hline Z9 & 0.963 & 0.878 & 0.947 \\
\hline Z10 & 0.955 & 0.972 & 0.958 \\
\hline Z11 & 0.955 & 0.930 & 0.831 \\
\hline Z12 & 0.956 & 0.958 & 0.794 \\
\hline
\end{tabular}

\section{Conclusion:}

Drug delivery system should deliver drug at a dictated by needs of the body over a specified period of time. The newer drug delivery system is being used to body distribution of drug with a view to reduce the toxicity of drug and deliver to their site of action. Floating drug delivery systems are retained in the stomach and are useful for drugs that are poorly soluble or unstable in intestinal fluid. Floating drug delivery system have a bulk density less than that of gastric fluids and so remain buoyant in the stomach without affecting the gastric emptying rate for a prolong period of time. About 15-35 $\%$ of HPMC can be used as a polymer in the extended release formulations. So, here the polymer was used in the range of $16-36 \%$. Sodium bicarbonate $(40 \%)$ is used as a gas generating agent. It can be used in the range of $25-50 \%$. The granules are prepared by wet granulation method. The prepared granules were evaluated for the bulk density, tapped density, bulkiness, angle of repose, compressibility index and hausner ratio. The values indicate good flow property. The compressed tablets were evaluated for hardness, uniformity of weight, friability, drug content, buoyancy lag time and duration of buoyancy. All the readings are within the prescribed limits.
References:

1. Agarwal $M$, Srinivasan $R$, Mishra A. A study on flocculation efficiency of okra gum in sewage waste water. Macromol Mat Eng 2001;9:560-63.

2. Singh B. Psyllium as therapeutic and drug delivery agent. Int J Pharm 2007; 334: 1-14.

3. Singh K, Kumar A, Langyan N, Ahuj M. Evaluation of Mimosa pudica Seed Mucilage as Sustained-Release Excipient. AAPS PharmSciTech 2009; 10(4):1121

4. Petropoulos GA. Fenugreek: The genus Trigonella. In: Petropoulus GA, (Ed.), Botany. London: Taylor and Francis; 2002.9-17.

5. A.O. Nur, and J. S. Zhang, Captopril floating and/or bioadhesive tablets: design and release kinetics, Drug. Dev. Ind. Pharm, 26: 965 - 969, (2000).

6. E. Rudnic, and J. B. Schwartz, Oral solid dosage forms In: Remington's Pharmaceutical Sciences. 18th Edition, Ed. Gennaro, A. R. Mack Publishing Company, Easton, Pennsylvania, USA, 1633-1665 (1990).

7. V. Iannuccelli, G. Coppi, MT. Bernabei, and R. Cameroni. Air compartment multiple-unit system for prolonged gastric residence. Part I. Formulation study, Int. J. Pharm. 174: 47-54 (1998).

8. Sood A and Panchaghula R: Design of controlled release delivery systems using modified pharmacokinetic approach: a case study for drugs having a short elimination half-life and a narrow therapeutic index, Int. J. Pharm, 2003; 261: $27-41$.

9. Hwang SJ, Park H, and Park K: Gastric retentive drug delivery systems, Crit Rev Ther Drug, 1998; 15: $243-348$. 